\title{
Observations on the Biology of Botrytis cinerea.
}

\author{
BY
}

F. T. BROOKS, B.A.,

Frank Smart Student, Cains College, Cambridge. Late Scholar, Emmanuel College.

\section{With four Figures in the Text.}

THOUGH the connexion between Botrytis cinerea and Sclerotinia Fuckeliana had been long surmised, no definite proof of the identity of these two forms was forthcoming until the recent appearance of a paper by Gy. de Istvánffi, entitled ' Études microbiologiques et mycologiques sur le rot gris de la vigne-Botrytis cinerea ou Sclerotinia Fuckeliana.' Istvánffi has come to the conclusion that Botrytis cinerea is indubitably the conidial stage of Sclerotinia Fuckeliana. This fungus causes a virulent disease of the fruit and foliage of the vine on the Continent. The diseased areas at first produce abundant conidiophores of the Botrytis type and sclerotia are formed later. Istvánffi has shown that these sclerotia, upon germination, produce either conidiophores of the Botrytis type or apothecia such as have long been known to characterize Sclerotinia Fuckeliana. In this country, Botrytis cinerea is generally found growing saprophytically upon the dead leaves and flowers of many plants. After being nourished in this way the mycelium has frequently the power of destroying living tissues by the secretion of a poisonous substance.

The group of fungi to which Botrytis cinerea belongs has been of particular interest to the plant pathologist ever since De Bary published his researches entitled 'Ueber einige Sclerotinien und Sclerotinienkrankheiten.' In that series of papers he dealt mainly with the life-history of Sclerotinia Sclerotiorm, especially in so far as it was the cause of a disease of the roots of Beta, Raphanus, and Daucus, and the foliage of Phaseolus and Petunia. This fungus has no conidial fructification, but produces abundant sclerotia, which germinate after a period of rest and give rise to apothecia. De Bary found that the ascospores were unable to cause direct infection of the living host-plant; if, however, the ascospores were sown upon some saprophytic medium, the young mycelium produced, upon 
germination, possessed the power of destroying living tissues. He concluded that this power lay in the secretion of some poisonous substance or substances by the fungal hyphae, the tissues thus disorganized serving as food material for the further development of the fungus. In regard to the disintegration of the tissues, De Bary states that two phenomena are to be distinguished, viz. the death of the protoplasmic bodies and the destruction of the cell-walls. He came to the conclusion that an enzyme is the specific agent of the latter, while the death of the protoplasmic bodies might be due either to an enzyme or to an acid, or to both working together.

Marshall Ward, in his work on 'A Lily Disease', found that a fungus nearly related to Botrytis cinerea, or possibly identical with it, attacked plants of Lilium candidum in a very similar manner to that of Sclerotinia Sclerotion mentioned above. He attributed the disorganization of the tissues of the Lily to a cellulose-dissolving enzyme secreted by the fungus. He found that the conidia could bring about direct infection of the leaves and flower buds, though he noticed that the attack was stronger if some saprophytic nourishment was at hand to invigorate the young germ-tubes. R. E. Smith, in a recent paper, puts forward the view that some such substance as oxalic acid is secreted by the fungus and is responsible for the primary destruction of the tissues.

Kissling, in 1889, published an account of a disease of Gentiana lutea caused by Botrytis cinerea. He found that the conidia could not bring about direct infection of the leaves, though the young germ-tubes readily attacked the stigmas and anthers of the flowers. Doubtless this was on account of the lack of cuticularization of these parts. It is noteworthy that the species of Sclerotinia which cause the 'mummy' fruits of various kinds of Vaccinium infect their hosts in the same way.

In 1899 Nordhausen investigated further the question as to whether Botrytis conidia can infect living tissues. He found that non-cuticularized organs such as the anthers and petals of the Tulip and Crocus, and Moss leaves succumbed readily to the attacks of the germinating conidia. Only under such a condition as the following, however, did it result that leaves could be attacked. He placed conidia on the leaves of Tradescantia kept in a damp chamber, and regulated the deposition of dew. When the amount of dew deposited was small, the spores caused infection. He explained this, and the non-infection when the deposition of dew was greater, by supposing that in the latter case the poisonous substance secreted by the germ-tubes was diluted beyond the minimum intensity necessary to cause infection. Nordhausen mentions a number of factors in regard to the disposition of the host which might render it liable to destruction by Botrytis. He suggests that plants which have become etiolated through being kept in darkness would succumb the more readily to the fungus; also that dying leaves of ordinary plants would offer less 


\section{Brooks.-Observations on the Biology of Botrytis cinerea. $48 \mathrm{I}$}

resistance to attack. However, he gives no details of infection under these conditions

In view of the uncertainty attaching to the power of infection of Botrytis conidia, the late Professor Marshall Ward suggested to me the advisability of investigating the matter again. At the outset of the work the growth of the fungus upon different media was tried. The results of this may be summarized as follows:-Upon grape extract stiffened with gelatine the fungus grew luxuriantly and produced abundant conidiophores of the normal type. Later, the structures known as 'organs of attachment' appeared in great abundance as brown specks, and occasionally sclerotia were produced.

In Klebs's solution, similarly prepared, the growth was sparse, only a few conidiophores of the normal type being produced. 'Organs of attachment' were rarely produced, and sclerotia were not observed. It was noticed that in succeeding cultures upon this medium the growth became somewhat more luxuriant. This points to the possibility of the fungus adapting itself in the course of time to a medium which was not originally favourable to its growth.

Upon bouillon with 10 per cent. gelatine the growth was comparatively feeble, and during the first three generations only conidiophores bearing microconidia were borne. This is additional evidence of the wellknown plasticity of Botrytis upon culture media. The microconidial form of fructification has been recorded and figured by several observers, notably by Istvánff, who obtained it upon glycerine cultures. In the fourth generation of the fungus upon the bouillon medium the growth was more luxuriant and the normal conidiophores were produced. It is not known whether this change in the mode of reproduction was dependent upon some alteration in the conditions of experiment, such as accounts for the different modes of reproduction in some Algae, as Klebs has shown. If this were the case, the alteration must have been a slight one, for the cultures were kept in a room where the obvious physical factors controlling the growth were the same. It may be that the fungus, having become accustomed during three previous generations to the bouillon medium, was sufficiently invigorated to produce again the normal type of conidiophore. No sclerotia and but few 'organs of attachment' were formed in the bouillon medium.

For the infection experiments Lettuce plants were almost exclusively used, as these are extremely susceptible to the attacks of Botrytis. When growing upon these plants the fungus produces abundant conidiophores of the normal type and, later on, sclerotia. At first, attempts were made to see whether the spores could directly infect the ordinary leaves. Thus spores from the grape extract medium were placed upon the leaves of normal plants kept uncovered in a greenhouse. In another series of ex- 
periments the spores were sown in drops of water upon the leaves. In no case, however, was infection brought about. Under the microscope it was seen that some of the spores had germinated. The short germtubes so produced soon collapsed. The explanation of this may be that the small amount of poisonous substance secreted at this young stage is insufficient to destroy normal tissues. A fuller discussion of this point will be gone into later in the paper. The same experiments were tried with plants which had been kept some days under a bell-jar and had therefore been living in a continually moist atmosphere. It might be expected that the tissues of such plants would be more easily penetrated by the secretions of the germ-tubes, but no case of infection was observed.

Kissling recorded the fact that the mycelium of Botrytis caused infection of a certain host the more speedily, the greater the number of 'generations' the fungus had lived on that host since its origin from a sclerotium. This suggested the possibility that spores derived from a mycelium which had lived a long time upon Lettuces might perchance be capable of infecting normal Lettuce leaves where spores derived from the grape extract cultures were impotent. Experiments were repeatedly tried with this end in view, but in no case was infection brought about. On the other hand, infection was in all cases induced by placing young mycelia in drops of the grape extract medium upon the healthy leaves. The young fungus invigorated in this way became the victor in its struggle with the green plant.

The effect of wounding normal plants was next tried. Leaves still attached to the plants were torn in various ways, and spores placed upon the wounded parts. A hot platinum needle was applied to certain of the leaves and spores placed upon the burnt areas. In every case infection ensued. Of course in such cases the juices which exude from the wounded areas provide saprophytic nourishment for the further development of the germ-tubes.

During these attempts to bring about infection by means of the spores, it was noticed that certain of the plants, several days after being experimented with, showed the well-known disease areas of Botrytis upon the lower leaves. It was observed that in all cases the leaves affected were becoming yellow. When the diseased area was small it could be seen that infection began at that part of the leaf upon which the spores had been originally placed. The plants which bore these infected areas on the yellowing leaves had been kept under bell-jars in bright light. It seemed fair to conclude from this observation that the spores were able to infect yellowing leaves although unable to infect those of normal green colour. This conclusion was tested repeatedly, and as often confirmed. It was apparent from the tests made that Botrytis conidia could bring about infection of leaves which had only just begun to turn yellow. To 
Brooks.-Observations on the Biology of Botrytis cinerea. 483

ascertain how soon after the inoculation with spores, of the leaf just beginning to turn yellow, the penetration of the germ-tubes began, the following method was adopted:-Leaves just beginning to turn yellow were inoculated with spores, and from day to day the areas of the leaves on which the spores had been placed, were cut out and fixed in Flemming's weaker solution, and afterwards microtomed and stained. Upon examination of the sections it was found that the germ-tubes had already begun to penetrate the tissues the first day after inoculation. The germtubes pierce the cuticle and soon ramify in the cells which they have destroyed, as will be seen in the accompanying figures. It will be observed in Fig. 3 that the nuclei of the developing hyphae are extremely numerous, but very small. In Fig. 4 the nuclei are seen under a greater magnification.

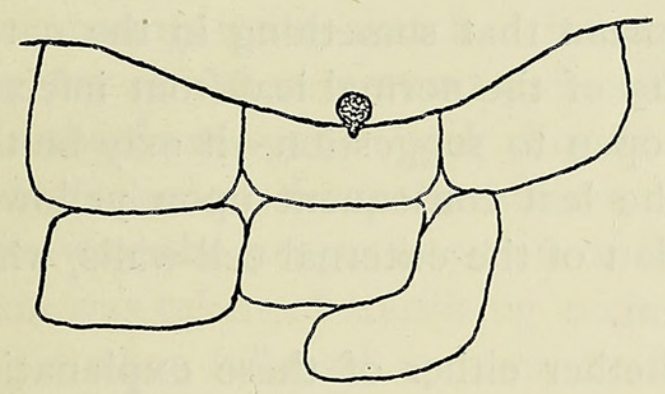

Fig 1.

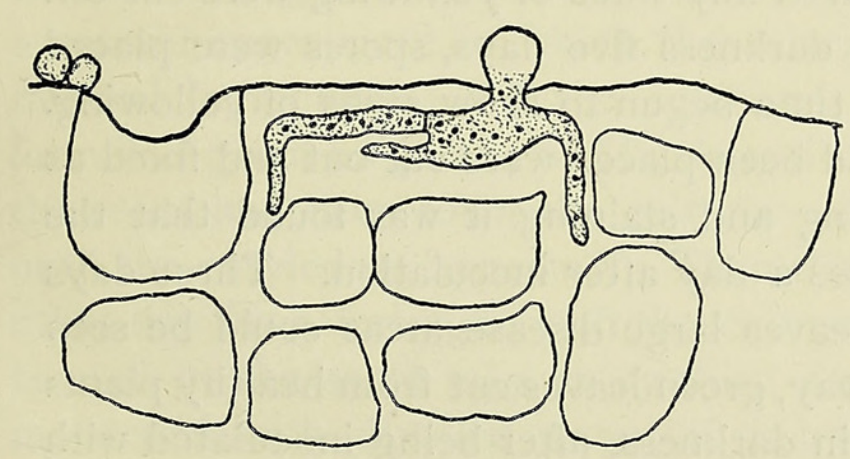

Fig 3

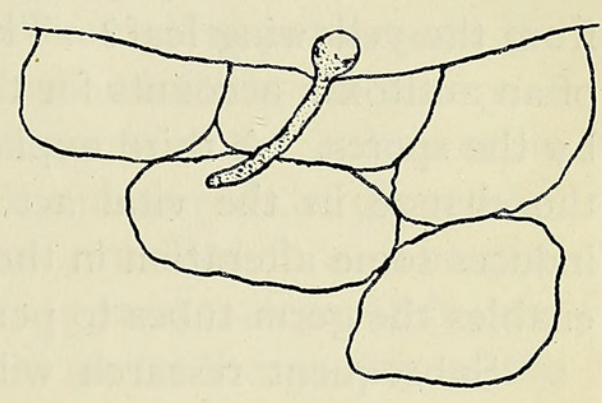

Fig 2.

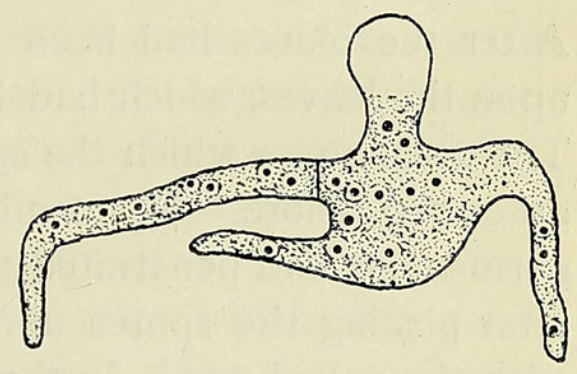

Fig 4.

These yellowing leaves must be considered to be in the incipient stage of decay, for they were never observed to recover their normal colour. They are by no means 'dead', however, if the term 'death' be applied to the state when the cells cease to be plasmolysable. These yellowing leaves live several days before they become flaccid and collapse. It would 
be interesting to know what is the exact physiological condition of these yellowing leaves. That the power of carbon assimilation is dwindling rapidly seems certain, for under the microscope the colour of the chlorophyll granules is seen to be fading. One naturally inquires what is the cause of the direct infection of the yellowing leaves and the non-infection of the normal green leaves.

It may be that some chemotropic substance present in the cells of the yellowing leaf attracts the germ-tubes, whereas no such chemotropic influence is exerted by the normal leaf. Recently, however, Fulton has thrown considerable doubt upon the positive chemotropism of fungal hyphae.

Or is it possible that in the case of non-infection of a normal leaf, some substance from the epidermal cells diffuses through the cuticle in sufficient quantity to neutralize the effect of the small amount of poisonous substance secreted by the germ-tubes, whereas no such substance diffuses from the yellowing leaf? This would mean that something in the nature of an antitoxin accounts for the immunity of the normal leaf from infection by the spores. A third explanation is open to suggestion-it may be that the change in the vital activities of the leaf consequent upon yellowing induces some alteration in the composition of the external cell-walls, which enables the germ-tubes to penetrate them.

Subsequent research will show whether either of these explanations is valid.

Similar experiments to those outlined above were tried with plants which had been placed in darkness. At the time of placing the plants in the dark-room, all leaves which showed any trace of yellowing were cut off. After the plants had been kept in darkness five days, spores were placed upon the leaves, which had by that time begun to show signs of yellowing. The areas upon which the spores had been placed were cut out and fixed as described before. Upon microtoming and staining it was found that the germ-tubes had penetrated the tissues a day after inoculation. Three days after placing the spores upon the leaves large disease areas could be seen with the naked eye. In the same way, green leaves cut from healthy plants and placed under damp conditions in darkness, after being inoculated with spores, showed the characteristic disease areas immediately after they had begun to turn yellow. F. F. Blackman has shown in his experiments upon the respiration of starved Cherry Laurel leaves, i. e. leaves cut off the plant and placed in darkness, that soon after the period of maximum $\mathrm{CO}_{2}$ production prior to death, the common mould fungus Penicillium begins to flourish upon the leaves. At this juncture the juices of the leaf-cells are escaping, and provide the necessary saprophytic nourishment for the spores of the moulds which are lurking on the surface. It seems from the experiments described above, that the time when Botrytis conidia cause infection 
of the starved leaves is earlier than the time when such a truly saprophytic mould as Penicillium begins to flourish upon them. This is in accordance with the view which considers Botrytis to be a hemi-saprophyte. Its mode of nutrition cannot be placed in the same category of sxprophytism with that of such a fungus as Penicillium or Eurotium; nor can it be considered a true parasite, for it kills tissues in advance of its own growth.

While the experiments already described were being carried on, another series was in progress, in which the Lettuce plants were grown under different conditions of mineral starvation. It was desired to ascertain whether plants, grown in a substratum which was deprived of certain mineral supplies, were more liable to infection by Botrytis conidia than plants grown in ordinary soil. Lettuce seeds were sown in fine sand, chemically pure, placed in circular glass jars. At the bottom of each jar a small inverted flower-pot had been placed in an inverted position, and passing through the hole in the flower-pot was a glass tube, as will be seen in the accompanying sketch. Some pieces of broken glass put around the flower-pot served to prevent the sand from falling and filling the air space within the flower-pot. Each day during the progress of the cultures the air was sucked up from the bottom of the jars by means of the glass tube. In this way the proper aeration of the roots was provided for. The precaution was taken of sterilizing each part of the apparatus separately, and each jar when fully set up was sterilized again prior to the sowing of the seeds. Black paper was bound round the outside of the jars in order to prevent the growth of Algae within.

The culture solutions chosen were those devoid of potassium, magnesium, nitrogen, and phosphorus, respectively, and of course there was a control experiment in which the solution used contained all the normal mineral ingredients. All the solutions were made up according to the formulae given on p. 224 of Macdougal's Textbook of Physiology. After the seeds had been sown the cultures were moistened with distilled water until the cotyledons appeared. Then the young plants were watered every other day for a fortnight with the culture solutions, after which they were treated in the same way every third day. On other days the sand was moistened with distilled water, if this was thought necessary. Care was taken to avoid any collection of liquid at the bottom of the jars, so there was no danger of the roots being water-logged. The cultures were placed under large bell-jars in a greenhouse, the temperature of which varied between $10^{\circ}$ and $20^{\circ} \mathrm{C}$. The plants grew well under the conditions of the experiment. Six weeks after sowing the seed each plant grown in the jar containing the normal mineral supplies, and in those devoid of nitrogen and magnesium respectively, possessed 4-5 ordinary foliage leaves, the largest being $\mathrm{I} .5 \mathrm{c.m}$. in diameter. The plants grown in sand devoid of phosphorus were about half the size of those just mentioned, while those 
deprived of potassium were intermediate in size between those described in the first category and the latter. In all cases, however, the plants appeared to be quite vigorous. One might suppose that after six weeks' active growth the influence of the reserve materials stored up in such seeds as those of the Lettuce would be greatly minimized; and that the absence from the soil of certain of the normal mineral constituents would be felt throughout the regions where metabolism was in progress. At this stage Botrytis spores derived from diseased Lettuces were placed directly upon the leaves of the different cultures, the precaution having been taken of cutting off any yellowing leaves present. In none of the plants, however, did any sign of infection ensue. The inoculations were repeated, the spores being placed this time in drops of water upon the leaves. There was the same negative result as before. The whole series of cultures was repeated twice, but in no case did any evidence come to hand that the deprivation of certain mineral substances from the soil would induce the plants grown in it to succumb to direct infection by the spores.

It is clear, therefore, that, even by a great reduction in the amount of certain mineral constituents available, no such change can be induced in the constitution of the green plant as would account for the penetration of the germ-tubes of Botrytis. One supposes that the amount of food material stored up in the seed, together with the water and mineral substances absorbed from the soil and the carbon fixed from the air, enables the ordinary plant machine to elaborate a certain amount of protoplasm. If, e. g. a certain mineral substance is deficient in quantity, a less amount of protoplasm will be formed, but the protoplasm produced under these conditions will be of the same 'quality' - if one can use such a term-as that produced under conditions of normal nutrition. And if the protoplasm of plants grown under conditions of mineral starvation is of the same 'quality' as that of plants grown under normal conditions, there is no likelihood that the constitution of the former plants will be such as to lead to infection by the germ-tubes of Botrytis.

The results here obtained may be compared with those of Marshall Ward in regard to the parasitism of Puccinia dispersa upon species of Brome grasses grown under conditions of mineral starvation. He found that starvation of the host had no appreciable effect upon the ability of this fungus to infect. Of course the method of infection of Botrytis cinerea is totally different from that of Puccinia dispersa, but the aim of the culture experiments was the same in each case. With Botrytis, whose conidia are unable to infect the leaves of the normal Lettuce plant, and with Puccinia dispersa, whose uredospores readily infect the Brome grass, the influence of mineral starvation of the host upon the inability or ability to cause infection, respectively, was nil. The work on Botrytis outlined here confirms Marshall Ward's view that 'whatever may be the 
causes at work in the living cell which confer immunity or predisposition on the species of host-plant, or which confer virulence or impotence on the spore, they lie deeper than nutrition.'

In conclusion, I would like to tender my hearty thanks for the help I have received in this work from the late Professor Marshall Ward and from Mr. F. F. Blackman and Mr. R. H. Biffen.

\section{Literature Cited.}

De Bary, A.: Ueber einige Sclerotinien und Sclerotinienkrankheiten. Bot. Zeit., I 886.

Fulton, H. R. : Chemotropism of Fungi. Bot. Gaz., vol, xli, 1906.

ISTVANFFI, GY. DE : Études microbiologiques et mycologiques sur le rot gris de la vigne-Botrytis cinerea ou Sclerotinia Fuckeliana. Annales de l'Institut Central Ampélologique Royal Hongrois, 1905 .

Kissling, E.: Zur Biologie der Botrytis cinerea. Hedwigia, I889.

KLeBS, G. : Die Bedingungen der Fortpflanzung bei einigen Algen und Pilzen., I 896.

Nordhausen, M. : Beiträge zur Biologie parasitärer Pilze. Jahr. wiss. Bot., I899.

Smith, R. E.: The Parasitism of Botrytis cinerea. Bot. Gaz., vol. xxxiii, I902.

Ward, H. Marshall : A Lily Disease. Ann. Bot., vol. ii, I888-89.

: Experiments on the Effect of Mineral Starvation on the Parasitism of Puccinia dispersa on species of Bromus. Proc. Roy. Soc., vol. $1 \times x i, 1902$. 


\section{$2 \mathrm{BHL}$ Biodiversity Heritage Library}

Brooks, F. T. 1908. "Observations on the biology of Botrytis cinerea." Annals of botany 22, 479-487. https://doi.org/10.1093/oxfordjournals.aob.a089184.

View This Item Online: https://www.biodiversitylibrary.org/item/232525

DOI: https://doi.org/10.1093/oxfordjournals.aob.a089184

Permalink: https://www.biodiversitylibrary.org/partpdf/318920

\section{Holding Institution}

Smithsonian Libraries

\section{Sponsored by}

Biodiversity Heritage Library

\section{Copyright \& Reuse}

Copyright Status: Not in copyright. The BHL knows of no copyright restrictions on this item.

This document was created from content at the Biodiversity Heritage Library, the world's largest open access digital library for biodiversity literature and archives. Visit BHL at https://www.biodiversitylibrary.org. 